\title{
Elaboração de estratégias neuropsicomotoras como ferramenta para a estimulação na educação infantil
}

\section{Development of neuropsychomotor strategies as a tool for stimulation in child education}

DOI: $10.46814 /$ lajdv3n6-010

Recebimento dos originais: 01/10/2021

Aceitação para publicação: 22/11/2021

\section{Taísa Bon Pereira}

Universidade Federal Fluminense - UFF

Curso de Graduação em Fonoaudiologia Nova Friburgo, Rio de Janeiro, Instituto de Saúde de Nova Friburgo no Departamento de Formação Específica em Fonoaudiologia FEF. Rua Dr. Silvio Henrique Braune, 22 - Centro, Nova Friburgo - RJ, 28625-650.

Brasil.

E-mail: taisa_bon@hotmail.com

\section{Cláudia da Silva}

Universidade Federal Fluminense - UFF

Docente do Departamento de Formação Específica em Fonoaudiologia, Nova Friburgo, Rio de Janeiro, Brasil.

Instituto de Saúde de Nova Friburgo no Departamento de Formação Específica em Fonoaudiologia FEF. Rua Dr. Silvio Henrique Braune, 22 - Centro, Nova Friburgo - RJ, 28625-650.

E-mail: claudia_silva@id.uff.br

\section{RESUMO}

O objetivo deste estudo foi elaborar estratégias neuropsicomotoras como ferramenta de estimulação para a educação infantil. A elaboração das atividades foi dividida em habilidades de coordenação motora global, coordenação motora fina, coordenação visomotora e contação de histórias. As atividades foram elaboradas com proposta de aplicação em 20 sessões, sendo desenvolvidas cinco atividades para cada habilidade. Sendo elas: Coordenação Motora Global composta pelas atividades de bola no quadro, bola por cima e bola por baixo, labirinto de barbante, unidos pelo bambolê e circuito. Coordenação Motora Fina composta por atividades de completar traços e figuras, alinhavo de imagens e vogais, quadro vocálico ilustrado, pontinhos coloridos e quebra-cabeça com espátulas de madeira. Coordenação Visomotora desenvolvida por atividades de identificar letras pelo direcionamento das suas posições, tabuleiro geométrico para a identificação de formas e direções, sequenciamento de formas e cores, conexão de botões, e organização de cores e posições. Realizada por último a Contação de histórias por meio dos objetos, desenhos e imagens trabalhados nas sessões anteriores associada a um tema pré-determinado. De acordo com os resultados, o estudo identificou que foi possível elaborar estratégias neuropsicomotoras e vincula-las com a estimulação para a educação infantil, de acordo com as evidências científicas abordadas no estudo.

Palavras-Chave: Aprendizagem, Desenvolvimento, Linguagem, Psicomotricidade, Educação infantil.

\section{ABSTRACT}

The objective of this study was to develop neuropsychomotor strategy as a stimulation tool for early child education. The elaboration of activities was divided into global motor skills, fine motor skills, 
visomotor coordination and storytelling. The activities were prepared with a proposal for application in 20 sessions, with five activities being developed for each area worked on. Being them: Global Motor Coordination composed of ball activities on the board, ball on top and ball on the bottom, string maze, united by the hula hoop and a circuit. Fine Motor Coordination consisting of activities to complete strokes and figures, basting images and vowels, illustrated vowel frame, colored dots and puzzle with wooden spatulas. Visomotor Coordination developed by activities to identify letters by directing their positions, geometric board for identifying shapes and directions, sequencing shapes and colors, connecting buttons, and organizing colors and positions. Lastly, Storytelling through objects, drawings and images worked in previous sessions associated with a predetermined theme. According to the results, the study identified that it was possible to develop neuropsychomotor strategies and link them with stimulation for early childhood education, according to the scientific evidence addressed in the study.

Keywords: Learning, Development, Language, Psychomotricity, Child education.

\section{CONSIDERAÇÕES INICIAIS}

A neuropsicomotricidade é uma ciência que estuda o corpo em movimento de acordo com a maturação do Sistema Nervoso Central (SNC) e suas relações com o mundo tanto interno quanto externo. Nessa abordagem o corpo é a origem para o desenvolvimento de fatores cognitivos, afetivos e orgânicos (Cardoso, Henderson, \& Capellini, 2014; Arraes, Cordeiro, Macedo, \& Soares, 2017; Fonseca, 2018).

O desenvolvimento infantil é um processo caracterizado por marcos, em que existem comportamentos esperados, de acordo com cada idade, sendo estes marcos, definidos por fatores biológicos, ambientais e socioeconômico. Os fatores biológicos são relacionados ao desenvolvimento neurocognitivo e orgânico do indivíduo, já os fatores ambientais seriam aqueles associados ao meio em que o indivíduo está inserido, e os fatores socioeconômicos dizem respeito as influências captadas pelo meio social, cultural e classificação econômica (Maronesi et al., 2015; Benetti et al., 2018).

De acordo com a literatura, nos primeiros anos de vida são identificados marcos do desenvolvimento em que acontecem grandes progressos nas áreas cognitivas, motoras, sociais e afetivas da criança. Essas áreas estão interligadas e são importantes para o desenvolvimento global e para o processo de aquisição da linguagem e da fala. Déficits durante o processo de aquisição podem acarretar, futuramente, dificuldades de aprendizagem no meio escolar, pois crianças com atraso do desenvolvimento neuropsicomotor estão propensas a apresentar um desempenho funcional inferior quando comparadas às crianças que não apresentam atraso (van der Maas et al., 2016; Oliveira et al., 2018; Ingwersen et al., 2019).

Assim, a neuropsicomotricidade é de extrema importância para a educação infantil, pois é por meio dela, vinculada as estratégias de estimulação, que a criança aprende a elaborar melhor seus 
movimentos, amplia a coordenação motora (global e fina), tais como o esquema corporal, equilíbrio, lateralidade, estruturação espacial, organização temporal e coordenação visomotora. A junção e o desenvolvimento de todos esses fatores de forma sincronizada e harmônica permite um desenvolvimento infantil mais pleno, além da oferta de subsídios para novos aprendizados pela exploração ao ambiente em que está inserido (Rossi, 2012; Fagaras, Rus, \& Vanvu, 2014; Sacchi, \& Metzner, 2019).

A coordenação motora global envolve grandes grupos musculares compostos por diferentes cadeias, responsáveis por movimentos amplos que abrangem o corpo todo, envolvendo o equilíbrio, a ação motora, noção espacial e temporal que, ao atuarem em conjunto permitem o desenvolvimento de ações como engatinhar, andar, correr, pular, desbravar novos espaços para potencializar aprendizados prévios, entre outras. Já a coordenação motora fina trabalha pequenos grupos musculares responsáveis por movimentos mais precisos, necessitando de uma força mínima para que ocorram, o que leva à uma melhor destreza manual, para a realização de movimentos como a pinça e a preensão (mãos e dedos), o que auxiliará futuramente no processo da escrita manual (Andrade, Barbosa, \& Bessa, 2017).

O esquema corporal torna-se responsável pela conscientização da criança sobre o próprio corpo e suas funções, o que possibilita adquirir controle sobre suas partes, e desenvolver a capacidade de movimentação e expressão por meio de seu corpo. Enquanto o equilíbrio é o responsável pela capacidade de sustentar o corpo e mantê-lo sobre uma base, dividido em estático, quando o corpo se encontra parado, em repouso, ou dinâmico, quando o corpo está em movimento (Amaro et al., 2009).

Outra função importante é a lateralidade, pois se refere ao conhecimento dos lados do corpo (direita/esquerda, em cima/embaixo, frente/atrás) e a preferência em utilizar mais um lado em detrimento ao outro. Por sua vez, a estruturação espacial possibilita à criança movimentar seu corpo, situar-se no espaço e ter consciência dos objetos que estão ao seu redor. Já a organização temporal está relacionada com a noção de tempo e espaço, diretamente ligada ao ritmo e inclui a execução de atividades como dançar, pular corda, ler e escrever (Aranha, 2016).

O direcionamento da lateralidade tem sido amplamente estudado durante o desenvolvimento infantil na aprendizagem, quanto a sua relação com a identificação de letras com posicionamento semelhantes, associado também a noção espacial e temporal. Alguns estudos identificaram déficit no desenvolvimento dessas habilidades correlacionados ao baixo desempenho em leitura e escrita, ocasionando erros de inversão e reversão de letras, omissão e de base ortográfica (Cardoso, Henderson, \& Capellini, 2014; Brown, \& Link, 2016, Zimermann, Moretto, 2021).

Como habilidade ainda mais refinada, associada a aprendizagem, e que se desenvolve juntamente as funções citadas, temos a coordenação visomotora, em que a criança necessita realizar a associação entre a visão e o ato motor. Atividades como a elaboração detalhada de desenhos, controle 
específico ao pegar um objeto e manipulá-lo, identificar objetos, letras e números como diferentes e semelhantes, apontando seus detalhamentos como referencial, e classificá-los em ordem quando solicitados ou relacionados a uma ação específica como a decodificação, são todas funções típicas e usuais na aprendizagem que envolvem a coordenação visomotora (Ventura, 2016; Howe et al. 2017; Cardoso, 2019; Gonçalves \& Sabatine, 2021).

O uso de estratégias com base neuropsicomotora tem sido utilizado com o intuito de auxiliar no processo de aprendizagem de forma integral, fazendo uso de atividades lúdicas, que tendem a despertar maior interesse, motivação e envolvimento da criança em realizá-las. Dessa forma, as habilidades desenvolvidas nestas estratégias direcionam-se para a aquisição e estimulação da coordenação motora ampla, lateralidade, ritmo, noção espacial, percepção corporal, equilíbrio, coordenação motora fina, percepção tátil-sinestésica, percepção figura-fundo, memória, sequência, seriação e coordenação visomotora (Teodorescu \& Popescu, 2014; Andrade, Barbosa, \& Bessa, 2017).

Tais habilidades se classificam como propulsoras para o desenvolvimento da linguagem oral e escrita, pois permitem a ampliação do léxico, estimulando a imaginação e criatividade, tal como, a atenção e interação entre as crianças e o aprendizado formal da leitura e escrita (Zimermann, \& Moretto, 2021; Gonçalves, \& Sabatine, 2021). No entanto, no Brasil ainda são escassos estudos que possibilitem direcionar o trabalho do profissional clínico e educacional, possibilitando o intercâmbio entre essas habilidades associadas aos avanços educacionais (Fonseca, 2018; Sacchi, \& Metzner, 2019).

De acordo com o exposto, o objetivo deste trabalho consistiu em elaborar estratégias neuropsicomotoras como ferramenta de estimulação para a educação infantil.

\section{ELABORAÇÃO DAS ESTRATÉGIAS}

As evidências científicas para a estruturação das atividades estão apoiadas na literatura, descrita por Amaro et al., 2009; Rossi, 2012; Maronesi et al., 2015; Aranha, 2016; Brown, \& Link, 2016; Andrade, Barbosa, \& Bessa, 2017; Howe et al. 2017; Oliveira et al., 2018; Negreiros, Sousa, \& Moura, 2018; Fonseca, 2018; Cardoso, 2019, entre outros. Tais estudos indicam ganhos na estimulação iniciada por atividades amplas, seguindo para as que necessitam de percepção refinada para sua realização, seja de aspectos motores, associados a coordenação motora global e fina, ou cognitivos, relacionados a percepção visomotora, ao processamento auditivo e visual, e a exploração da linguagem pelo uso do vocabulário. Ou seja, a elaboração das estratégias seguiu a ordem de desenvolvimento psicomotor e as aptidões cognitivas adquiridas ao longo do desenvolvimento infantil (Rotta, Ohlweiler, \& Riesgo, 2011). 
Para tanto, a proposta de intervenção desenvolvida iniciou com atividades relacionadas a coordenação motora global, seguindo para a coordenação motora fina, especificando-se por meio da coordenação visomotora, finalizando com a associação do vocabulário desenvolvido nas práticas anteriores para a contagem e recontagem de histórias.

A proposta foi realizada com a estruturação de cinco estratégias distintas para cada habilidade trabalhada, o que originou 20 atividades, com aplicabilidade em 20 sessões, com duração média de 30 minutos de execução, para realização individual, em dupla e/ou em grupos. Sendo assim, as atividades foram elaboradas de acordo com cada etapa proposta e descrita a seguir.

\subsection{COORDENAÇÃO MOTORA GLOBAL}

1) Nome da atividade: Bola no quadro. Objetivo: Desenvolver a coordenação motora global (lateralidade, noção de espaço e ritmo) associado ao estímulo do processamento auditivo. Descrição: Para a realização desta atividade, serão necessários uma bola (dente de leite), um quadro como delineador de espaço e um marcador para quadro branco. Deverão ser desenhados três quadrados neste quadro, um no canto superior esquerdo, um no centro e outro no canto inferior direito. Aplicação: Esta atividade será realizada individualmente. As crianças deverão fazer uma fila. A criança que estiver realizando a atividade deverá ficar em frente ao quadro, escutar a instrução do aplicador, que deverá estar posicionado ao lado da criança, e arremessar a bola no quadro, conforme foi instruído. As instruções podem ser aleatórias para cada criança, sendo que, cada uma deverá realizar os três arremessos diferentes. As instruções que deverão ser dadas são: "Jogue a bola no canto superior do quadro com a mão esquerda", “jogue a bola no centro com as duas mãos" e "jogue a bola no canto inferior com a mão direita".

2) Nome da atividade: Bola por cima, bola por baixo. Objetivo: estimular a coordenação motora global (noção espacial e lateralidade) e trabalho em equipe. Descrição: A atividade deverá ser realizada em equipe, num local com espaço amplo, sem obstáculos e com piso linear. As crianças deverão formar uma fila, de modo que fique uma atrás da outra, deixando um espaço entre elas para conseguirem movimentar os braços para frente e para trás. Será utilizada uma bola de tamanho médio. Aplicação: A bola ficará na mão da primeira criança da fila, esta deverá começar passando a bola para trás por cima da cabeça para a segunda criança, que deverá pegar a bola e passá-la para trás por baixo das pernas para a terceira criança e assim, sucessivamente, alternando a passagem da bola entre por cima da cabeça e por baixo das pernas. Quando chegar na última criança, esta deverá ir para o início da fila e recomeçar a realização da atividade, que só terminará quando a criança que estava no início da fila no começo da atividade, voltar para o mesmo lugar com a bola em mãos. 
3) Nome da atividade: Labirinto de barbante. Objetivo: trabalhar a coordenação motora global (equilíbrio, ritmo e percepção corporal). Descrição: Fios de barbante deverão ser amarrados em estruturas firmes e seguras, com alturas, distâncias e sentidos diferentes, formando um labirinto. Aplicação: Está atividade poderá ser realizada individualmente ou em dupla, sendo que, uma criança não poderá auxiliar no desempenho da outra. A criança deverá passar por todos os obstáculos feitos com barbante, até chegar ao final do labirinto.

4) Nome da atividade: Unidos pelo bambolê. Objetivo: estimular a coordenação motora global (percepção corporal, lateralidade, equilíbrio e ritmo) e o trabalho em equipe. Descrição: Esta atividade será realizada em equipe. Deverá ser realizada num espaço amplo, sem obstáculos e com piso linear. Para esta atividade será necessário um bambolê. Aplicação: As crianças deverão dar as mãos para formação de uma roda. O bambolê deve ser colocado em diagonal sobre os ombros de uma criança. A partir disso, elas precisarão movimentar o bambolê para que este percorra a roda toda, por meio dos movimentos corporais, sem ninguém soltar as mãos, até o bambolê chegar ao local de partida.

5) Nome da atividade: Circuito. Objetivo: Desenvolver a coordenação motora global (ritmo, percepção corporal, equilíbrio, noção espacial e lateralidade). Descrição: O circuito será formado por 4 atividades diferentes, sendo elas, pular corda, boliche com o pé, bola na caixa e zigue-zague com cones. Estas atividades deverão ser montadas em um espaço amplo, sem obstáculos e com piso linear. O espaço deve ser dividido em 4 áreas, numeradas de 1 a 4, e em cada área deverá estar estruturada uma atividade relacionada com a sequência proposta. A primeira atividade será "pular corda". A segunda atividade será "boliche com o pé”, onde 6 pinos de boliche ficarão dispostos da seguinte forma: um pino na frente, dois no meio e três atrás, todos eles deverão estar justapostos em formato de um triângulo. A bola para arremesso deverá estar posicionada a uma distância de 1,5 a 2 metros dos pinos. A terceira atividade será "bola na caixa", deverá ter uma caixa, que pode ser de papelão, com comprimento e largura de aproximadamente 50 centímetros. Há uma distância de 1 metro deverá ter um recipiente com 4 bolas (preferencialmente bola de tênis), que devem ser lançadas no alvo (caixa de papelão). A quarta atividade será o "zigue-zague estruturado com 6 cones", dispostos em uma direção reta, com espaços de aproximadamente 50 centímetros um do outro. Aplicação: As crianças deverão formar uma fila. Cada criança deverá realizar cada uma dessas atividades individualmente, seguindo a ordem sequencial de atividades. Na atividade de pular corda, a criança deverá pegar a corda que estará na área 1 e pular por 10 vezes com movimentos coordenados e saltos ritmados. Depois irá para a área 2, onde deverá chutar a bola para conseguir derrubar os 6 pinos de boliche, o número de tentativas realizadas pela criança deve ser correspondente ao suficiente para derrubar todos os pinos. Após realizar esta atividade, irá para a área 3, em que precisará arremessar as 4 bolas que estarão num recipiente dentro da caixa, sendo assim, a criança deverá acertar as bolas no alvo (caixa de papelão) 
para finalizar esta atividade e avançar para a área 4, onde deverá caminhar em zigue-zague entre os cones, indo e voltando para completar o circuito. Assim que a primeira criança terminar de realizar o circuito, a próxima deverá iniciá-lo.

\subsection{COORDENAÇÃO MOTORA FINA}

1) Nome da atividade: Completando traços e figuras. Objetivo: Desenvolver a coordenação motora fina (preensão e noção de espaço), ampliação de vocabulário. Descrição: Esta atividade é composta por três imagens diferentes. No primeira, há uma coluna com seis frutas diferentes, sendo elas, maçã, uva, laranja, melancia, banana e pera. Paralelamente há outra coluna com as mesmas frutas, ambas estão ligadas por traços pontilhados distintos. Na segunda imagem, há seis figuras diferentes: folha, bola, cereja, borboleta, flor e bala. Cada figura está desenhada continuamente pela metade e a outra metade está pontilhada. A terceira imagem possui as mesmas figuras do segundo, sendo que, as imagens estão desenhadas parcialmente por traços contínuos. Aplicação: As três partes desta atividade serão aplicadas individualmente, onde cada criança deverá receber uma imagem em cada etapa separadamente. Na primeira imagem, a criança deverá identificar/nomear cada fruta e cobrir os diversos pontilhados para ligar uma fruta a outra igual. Na segunda imagem, as figuras deverão ser identificadas/nomeadas e após, os tracejados de cada figura deverão ser cobertos. Na terceira imagem, a criança desenhará a parte que falta para completar cada figura, sendo que, nesta etapa a criança não terá pista visual para completar as imagens.

2) Nome da atividade: Alinhavo das vogais. Objetivo: Reconhecer as vogais, estimular a coordenação motora fina (movimento de pinça e ordenação) e ampliar vocabulário. Descrição: A atividade é composta pelas cinco vogais em tamanho maiúsculo, formato caixa alta, recortadas em papel cartão plastificado de diversas cores, e por barbantes. Cada vogal possuirá vários furos alinhados em todo o entorno da letra. Aplicação: A criança deverá reconhecer as vogais e a cor de cada uma e passar o barbante pelas aberturas feitas em cada vogal, reconstruindo assim, seu formato. Enquanto a vogal é delineada pelo barbante a criança deve ser induzida a falar palavras que se iniciem com cada vogal específica.

3) Nome da atividade: Quadro vocálico ilustrado. Objetivo: Reconhecer as vogais, estimular a coordenação motora fina (orientação espacial e preensão do lápis), organização em categorias e ampliação lexical. Descrição: A atividade possui um quadro dividido em cinco colunas e cinco linhas, em que na primeira coluna há as vogais pontilhadas e nas demais, diversas figuras de cinco categorias diferentes: animais, frutas, objetos, meios de transporte e locais. Na linha de cada vogal há quatro figuras que iniciam com a mesma. Na linha da vogal "A", as figuras são: abelha, abacaxi, arara e avião. Na vogal "E": elefante, escada, esquilo e escola. Na vogal "I": injeção, igreja, isqueiro e ilha. Na vogal 
“O”: óculos, onça, ônibus e ovelha. Na vogal "U”: urso, urubu, uva e unicórnio. Aplicação: Cada criança receberá uma folha com o quadro contendo as vogais e imagens que deverão ser identificadas. Logo após, deverá cobrir o pontilhado das vogais e pintar as imagens correspondentes a cada vogal. As vogais e figuras serão recortadas, respeitando as linhas que as dividem no quadro. Serão dadas a cada criança seis pranchas, que estarão identificadas em seis categorias diferentes: vogais, animais, frutas, objetos, meios de transporte e locais. As vogais e figuras recortadas deverão ser coladas em cada prancha, respeitando a categoria de cada uma. Após a execução das etapas anteriores, a criança deverá escrever novas palavras que comecem com as vogais.

4) Nome da atividade: Pontinhos coloridos. Objetivo: Desenvolver a coordenação motora fina (preensão e noção de espaço), atenção, planejamento e organização. Descrição: Esta atividade é composta por três imagens. A primeira imagem é uma maçã, a segunda imagem um castelo e a terceira uma paisagem composta por uma árvore, um sol, nuvens, um pássaro, flores e grama. Todas essas imagens possuem vários pequenos círculos dentro de seus limites. Para a realização dessa atividade serão necessárias as três imagens impressas individualmente em folha A4, tinta guache e hastes flexíveis com pontas de algodão. Aplicação: A atividade deve ser realizada individualmente, sendo que cada criança receberá as três imagens, hastes flexíveis com pontas de algodão e tinta guache de diversas cores, podendo formar grupos para facilitar a utilização da tinta guache. A haste flexível com ponta de algodão deve ser molhada na tinta guache, e usando esta haste com tinta, a criança deverá preencher os pequenos círculos que estão nas imagens, tentando respeitar ao máximo o limite desses círculos e adequando as cores correspondentes às imagens.

5) Nome da atividade: Quebra-cabeça com espátulas de madeira. Objetivo: Desenvolver a coordenação motora fina (movimento de pinça), estimular a percepção tátil e visual, percepção figurafundo e trabalhar memória, sequência e seriação. Descrição: Esta atividade é composta por vinte quebra-cabeças formados por espátulas de madeira com imagens de animais: foca, galo, gato, leão, pato, rato, peixe, porco, zebra, cavalo, coelho, girafa, jacaré, macaco, pássaro, cachorro, elefante, borboleta, tartaruga e hipopótamo. Cada espátula possui uma letra que forma o nome do animal na parte inferior e em cima uma parte do animal desenhada. Aplicação: Inicialmente, os quebra-cabeças devem ser apresentados às crianças montados e os animais devem ser identificados/nomeados. As crianças devem ser divididas em quatro grupos, cada grupo receberá cinco quebra-cabeças, todos devem estar desmontados e com todas as peças dos animais misturadas ao serem entregues. Os grupos devem ser classificados pelo orientador em: grupo amarelo, grupo azul, grupo verde e grupo vermelho. Os grupos receberão os seguintes quebra-cabeças: Grupo amarelo: foca, pato, porco, girafa e hipopótamo; Grupo azul: gato, peixe, cavalo, pássaro e tartaruga; Grupo verde: rato, leão, jacaré, 
coelho e borboleta; e Grupo vermelho: galo, zebra, macaco, elefante e cachorro. Os grupos devem montar todos os quebra-cabeças corretamente (Figura 1).

Figura 1- Representação das imagens e formação das palavras

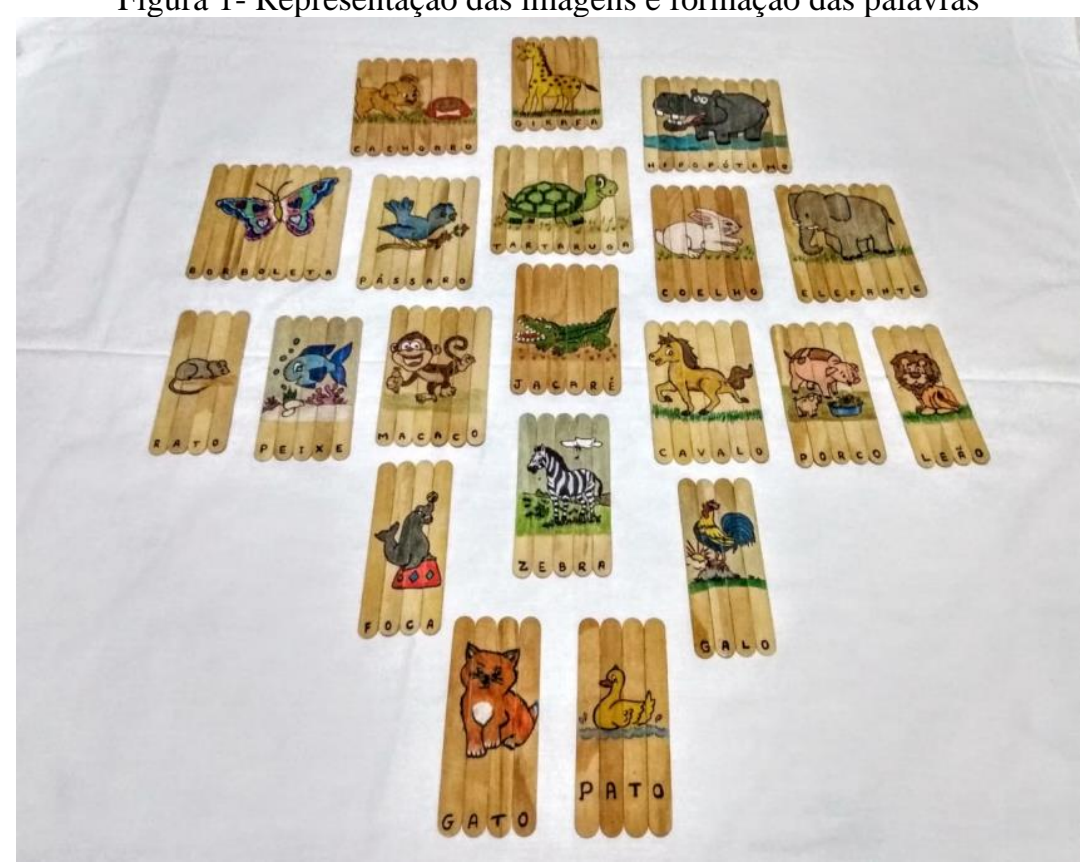

Fonte: elaborado pelas autoras

\subsection{COORDENAÇÃO VISOMOTORA}

1) Nome da atividade: Aprendendo a diferenciar. Objetivo: Desenvolver a percepção visomotora de letras, setas em cores diferentes; trabalhar atenção e planejamento. Descrição: A atividade contém uma prancha, em que no início há uma legenda com as letras "b", "p", "d" e "q". Cada letra é representada por uma seta com diferentes cores e direções. A letra "b" corresponde à uma seta vermelha indicando para cima, a letra " $p$ " corresponde à uma seta azul indicando para a direita, a letra "d" corresponde à uma seta amarela indicando para baixo e a letra "q" corresponde à uma seta verde indicando para a esquerda. Aplicação: Cada criança receberá uma prancha (Figura 2), onde deverá identificar as letras "b", "p", “d” e "q" e as setas com cores e sentidos diferentes, apresentadas em ordem aleatória. A atividade será realizada individualmente, sendo que abaixo de cada letra a criança deverá desenhar a seta de acordo com a letra correspondente. 
Figura 2 - Disposição das letras e marcações visuais (setas coloridas

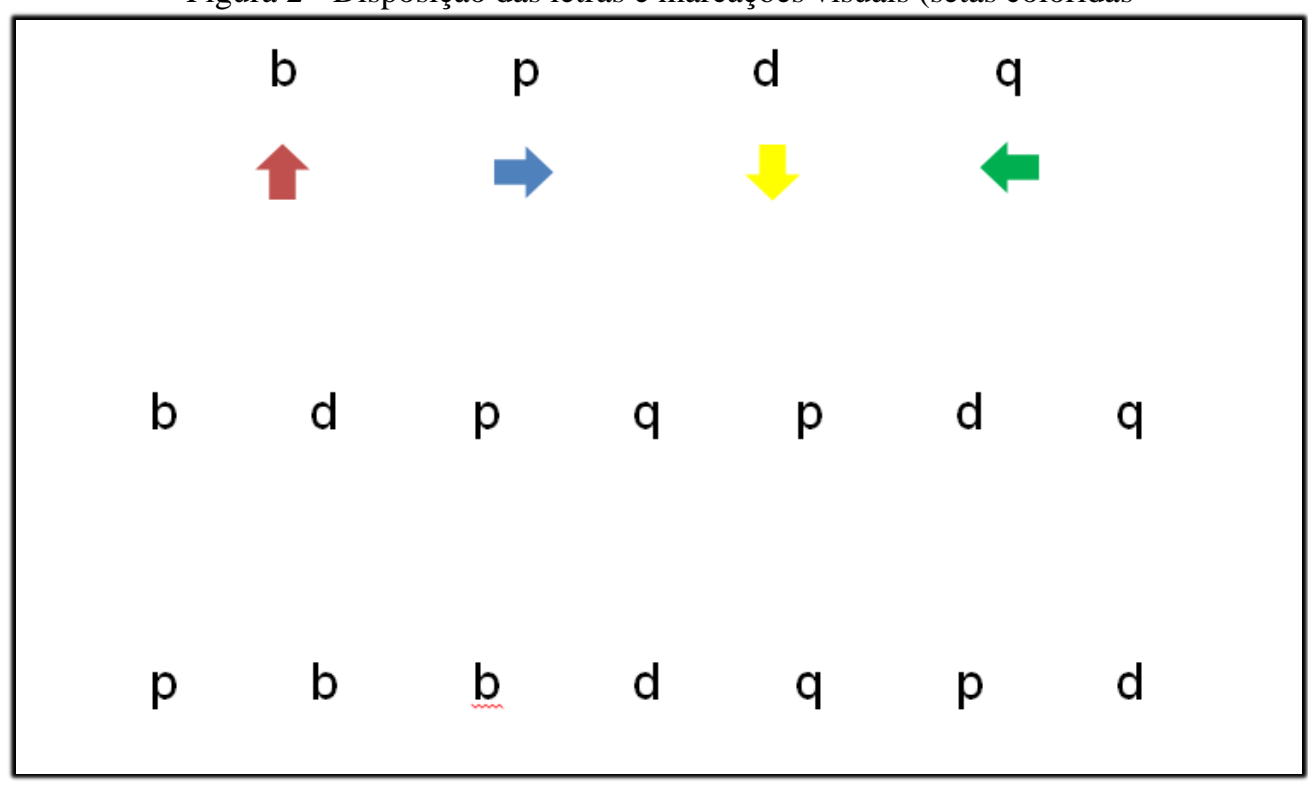

Fonte: elaborado pelas autoras

2) Nome da atividade: Tabuleiro geométrico. Objetivo: Desenvolver a percepção visual associada à coordenação motora fina (movimento refinado de pinça), atenção e planejamento. Descrição: A atividade é composta por quatro figuras geométricas distintas, sendo elas, círculo, triângulo, quadrado e losango e quadro linhas posicionadas de formas diferentes, horizontal, vertical, diagonal inclinada para a direita e diagonal inclinada para a esquerda. As imagens e as linhas de posicionamento serão apresentadas em um tabuleiro quadriculado. Na primeira coluna vertical há quatro formas geométricas diferentes e na primeira coluna horizontal, há linhas em distintas direções. Cada forma contém uma linha diferente, que deverão ser colocados no espaço correspondente. Aplicação: Serão apresentadas as formas geométricas e as linhas para as crianças, que deverão identificá-las separadamente uma a uma. Cada criança receberá um tabuleiro quadriculado com apenas a primeira coluna e a primeira linha preenchidas. Os outros espaços deverão estar em branco. As figuras geométricas cobertas com as linhas serão entregues separadamente para serem posicionadas nos espaços correspondentes, dessa forma cada criança irá receber uma prancha com as formas e linhas posicionadas e será orientada a reproduzi-las (Figura 3). A aplicação dessa atividade será realizada de forma individual. 
Figura 3 - Relação dos traços, formas e posições trabalhadas

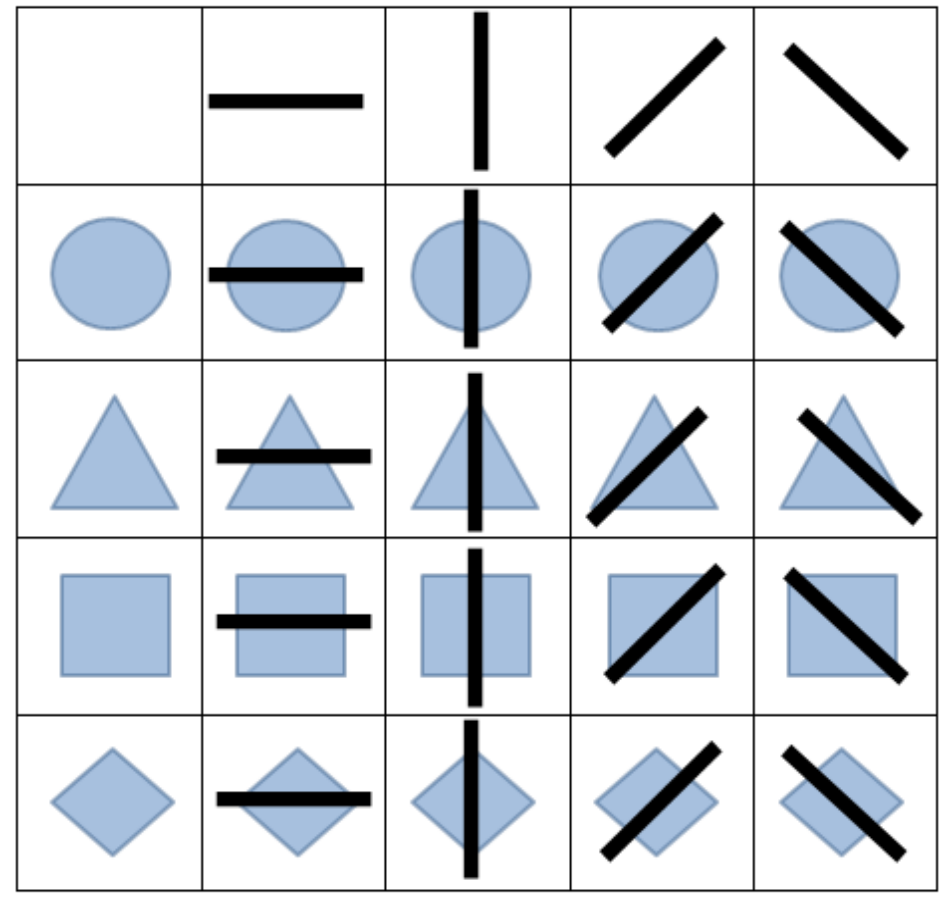

Fonte: elaborado pelas autoras

3) Nome da atividade: Formas e cores. Objetivos: Desenvolver a percepção visual, coordenação motora fina, ampliar vocabulário, atenção e planejamento. Descrição: A atividade possui 4 palitos com 4 formas diferentes confeccionados em papel cartão plastificado de várias cores, que foram coladas em palitos. Possui também uma folha com as formas desenhadas correspondentes a cada palito. No primeiro palito há um retângulo verde, um círculo vermelho, um triângulo amarelo e um quadrado azul. No segundo, um quadrado vermelho, um triângulo verde, um círculo roxo e um retângulo azul. No terceiro, um círculo amarelo, um retângulo roxo, um quadrado verde e um triângulo vermelho. No quarto palito, há um quadrado azul, um círculo verde, um retângulo vermelho e um triângulo roxo. Aplicação: Esta atividade deverá ser realizada individualmente o em duplas, em que cada criança irá receber os quatro palitos diferentes e a folha com as formas desenhadas. As crianças deverão identificar as formas e cores presentes em cada palito e após colocar o palito sobre a folha, no local correspondente às formas e cores (Figura 4). 


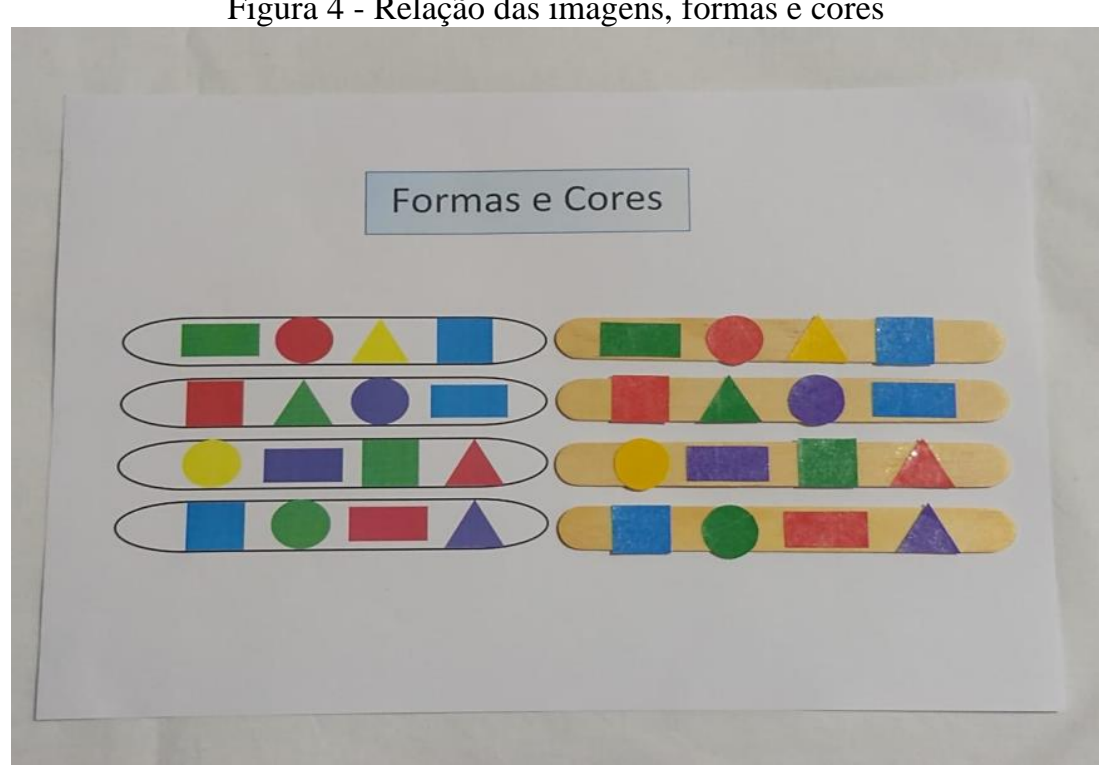

Fonte: elaborado pelas autoras

4) Nome da atividade: Conexão de botões. Objetivo: Desenvolver a percepção visual associada à coordenação motora fina (movimento de pinça, força manual e equilíbrio), atenção e planejamento. Descrição: Em um tabuleiro feito de papelão, deverão haver diversos pares diferentes de botões, de modo que a distância entre os botões iguais não seja muito grande. Esses botões precisarão estar fixos nesse tabuleiro. Além disso, também serão necessários elásticos, com a quantidade equivalente ao número de pares de botões. Aplicação: Esta atividade pode ser realizada em pequenos grupos, cada grupo receberá um tabuleiro com os botões e os elásticos e os elásticos deverão ser colocado em volta dos botões iguais, fazendo uma conexão entre estes.

5) Nome da atividade: Organizando cores e posições. Objetivo: Desenvolver a percepção visual, a coordenação motora fina (movimento de pinça), atenção, memória de curto prazo e planejamento. Descrição: Esta atividade é formada por uma imagem orientadora e nove hastes flexíveis com pontas de algodão, com as pontas coloridas em seis cores diferentes (amarelo, azul, branco, preto, verde e vermelho). Cada haste está pintada em suas pontas por cores diferentes (Preto e amarelo, Verde e branco, Vermelho e azul, Branco e vermelho, Verde e amarelo, Azul e preto, Preto e branco, Amarelo e azul, Vermelho e verde), não havendo nenhuma haste colorida igual à outra. Na imagem orientadora haverá, ilustrada, as três diferentes composições das hastes em posições e cores diferentes. Na primeira composição, haverá uma haste em sentido horizontal, com a ponta vermelha para a esquerda e a ponta azul para a direita, uma haste vertical, com a ponta preta para cima e a ponta amarela para baixo, e uma haste diagonal com a ponta verde inclinada para cima e para a esquerda e a ponta branca inclinada para baixo e para a direita. As pontas vermelha, preta e verde devem estar bem próximas. Na segunda composição haverá uma haste vertical com a ponta branca para cima e a ponta vermelha para baixo, 
paralela a essa haste em uma distância de aproximadamente 5 centímetros, haverá outra haste em sentido vertical com a ponta verde para cima e a ponta amarela para baixo e disposta sobre essas duas hastes, haverá uma terceira, em posição diagonal, com a ponta azul para cima e para a esquerda e a ponta preta para baixo e para a direita. Na terceira composição, haverá uma haste diagonal com a ponta preta para baixo e para a esquerda e a ponta branca para cima e para a direita, outra haste deverá ser posicionada em diagonal, com a ponta amarela para cima e para a esquerda e a ponta azul para baixo e para a direita, de modo que a ponta amarela fique em contato com o meio da haste anterior, e por fim, a última haste deve ser posicionada em diagonal com a ponta vermelha para baixo e para a esquerda e a ponta verde para cima e para a direita, sendo que a ponta vermelha deve estar posicionada na parte medial da haste anterior. Aplicação: Esta atividade deverá ser realizada individualmente. Cada criança receberá a imagem orientadora e as nove hastes com as pontas coloridas diferentemente. A criança deverá reproduzir as composições de acordo com os modelos ofertados, seguindo corretamente as posições e cores das hastes de modelo.

\subsection{CONTAGEM E RECONTAGEM DE HISTÓRIAS}

1) Nome da atividade: Os animais. Objetivos: Estimular a imaginação, desenvolver a linguagem narrativa, ampliação do vocabulário, atenção e a interação. Descrição: Para a realização desta atividade, será necessária que a atividade "quebra-cabeça com espátulas de madeira" tenha sido realizada anteriormente. As crianças deverão manter os mesmos grupos e deixar sobre a mesa os quebra-cabeças de animais montados. Aplicação: Cada grupo deverá contar uma história que apresente todos os animais que foram montados, sendo possível que um grupo de continuidade a histórias produzidas por outros grupos.

2) Nome da atividade: João e Maria. Objetivos: estimular a imaginação, desenvolver a linguagem narrativa, o discurso e ampliar o vocabulário. Descrição: Esta atividade é composta por uma folha A4 contendo a parte inicial da história "João e Maria" escrita pelos Irmãos Grimm. Deve ser apresentado oralmente e por escrito o início da história e solicitado as crianças que completem a mesma. Aplicação: Está atividade deverá ser realizada individualmente, onde cada criança receberá a folha com a parte inicial da história "João e Maria” em imagens ou escrita. Cada criança deverá reescrever ou narrar um novo desenvolvimento e conclusão, diferente da história original.

3) Nome da atividade: Diversão. Objetivos: Estimular a criatividade e imaginação, desenvolver a linguagem narrativa, ampliar vocabulário, construção frasal, a atenção e a memória. Descrição: As crianças deverão fazer uma roda e serão apresentadas três imagens. A primeira será de um parque de diversões, a segunda de um circo e a terceira de um zoológico. Aplicação: A partir das imagens, as 
crianças começarão a narrar uma história relacionada ao "Parque de diversões", em seguida ao "Circo" e após, ao "Zoológico", fazendo uma conexão das histórias contadas entre essas três imagens, sendo que uma criança deverá complementar a história da outra e inserir novos elementos relacionados às figuras que não estão presentes na imagem. Lembrando que novos personagens podem ser acrescentados.

4) Nome da atividade: Teatro com dedoches. Objetivos: Estimular a criatividade e imaginação, desenvolver a linguagem oral, incentivar a atenção e a interação. Descrição: Para a realização desta atividade deverão haver dedoches com animais do fundo do mar (Ex.: baleia, peixe, cavalo marinho, caranguejo e golfinho) e da fazenda (Ex.: coelho, vaca, rato, sapo, cachorro e pato), deverá haver um painel feito de caixa de papelão com tema de fundo do mar de um lado e tema de fazenda do outro, ambos com cortina no espaço que terá no meio para a apresentação do teatro. As crianças serão divididas em quartetos e cada criança deverá escolher um dedoche, de acordo com o tema escolhido. Aplicação: Cada quarteto deverá escolher seus dedoches, colocá-los no dedo indicador e, em seguida, posicionar os braços atrás do painel. O grupo deverá criar uma história, que será apresentada às outras crianças, dialogando entre si e movimentando os dedos, para dar "vida" aos dedoches. Assim que terminar, será a vez do próximo quarteto. Pode ser realizado um sorteio pelo aplicador para ordem de apresentação.

5) Nome da atividade: Faça sua história. Objetivo: estimular a criatividade, imaginação e trabalhar a escrita ou narrativa. Descrição: Para esta atividade, serão utilizadas folhas no formato A4, lápis de escrever e lápis de cor. As folhas A4 deverão ser recortadas ao meio e distribuídas, sendo que, cada criança deverá receber de 6 a 8 folhas recortadas ao meio. Aplicação: Cada criança deverá criar sua própria história com tema livre. A criança poderá produzir uma parte escrita e uma parte desenhada, contextualizando-as ou só realizar somente desenhos para contar sua história, caso ainda não saiba escrever. Os desenhos deverão ser pintados com lápis de cor. Ao final, as folhas serão reunidas corretamente e grampeadas na lateral, ficando no formato de um livro.

\section{CONSIDERAÇÕES FINAIS}

Espera-se que as estratégias neuropsicomotoras elaboradas para estimulação da educação infantil tenham eficácia e impacto positivo na aprendizagem escolar, assim como para o desenvolvimento corporal e da destreza motora, pois as áreas de desenvolvimento infantil estão interrelacionadas. Sendo assim, estimulando o desenvolvimento neuropsicomotor, espera-se que haja progresso reflexo em outras áreas do desenvolvimento infantil.

As atividades elaboradas possuem grande relevância para a educação infantil, ao propor a estimulação dos aspectos psicomotrizes, da linguagem, memória, atenção, organização e planejamento 
da criança, espera-se promover um melhor desempenho na aprendizagem, na capacidade motora e na percepção corporal, preparando a criança para o aprendizado da escrita manual, enquanto assume um papel facilitador para a alfabetização.

Dessa forma, pretende-se com a aplicação dessas estratégias, realizar um trabalho propulsor que vise auxiliar no trabalho educacional desenvolvido na escola, uma vez que tais atividades são tidas como preditoras para as aprendizagens mais complexas. Lembrando que tais estratégias podem ser adaptadas de acordo com a realidade clínica e educacional de cada profissional que atua no desenvolvimento infantil.

A próxima etapa deste trabalho consiste na validação das estratégias por análise de conteúdo e na aplicação das mesmas em uma amostra pré-definida para a realização do estudo piloto. Em seguida será realizada a coleta de dados com escolares pertencentes a pré-escola e ensino fundamental I, visando verificar a eficácia das estratégias para esta população. 


\section{REFERÊNCIAS}

Amaro, K. N., Santos, A. P. M., Brusamarello, S., Xavier, R. F. C., \& Neto, F. R. (2009). Validação das baterias de testes de motricidade global e equilíbrio da EDM. Revista Brasileira de Ciências e Movimento, 17(2), 1-17. doi:10.18511/rbcm.v17i2.1018

Andrade, A. S. S., Barbosa, C. C., \& Bessa, S. (2017). A importância do estímulo ao desenvolvimento da coordenação motora global e fina. Anais do Congresso de Iniciação Científica Estágio e Docência do Campus Formosa. Prática pedagógica e a formação docente: teoria e realidade. Universidade Estadual de Goiás, GO, Brasil. Recuperado de https://www.anais.ueg.br/index.php/ciced/article/view/10507

Aranha, M. L. (2016). A importância da ludicidade e da psicomotricidade para a educação infantil (Trabalho de Conclusão de Curso - Licenciatura Plena em Pedagogia). Universidade Federal da Paraíba, João Pessoa, Prasil. $\quad$ PE, Recuperado de https://repositorio.ufpb.br/jspui/bitstream/123456789/1770/1/MLA12122016

Arraes, C. L. B., Cordeiro, E. L. M., Macedo, J. L., \& Soares, G. A. (2017). Compreendendo a Psicomotricidade. Id on Line Revista Multidisciplinar e de Psicologia, 11(36), 284-294. Recuperado de https://idonline.emnuvens.com.br/id/article/view/789

Benetti, I. C., Barros, P. H. P., Wilhelm, F. A., Deon, A. P. R., \& Junior, J. P. R. (2018). Psicomotricidade e desenvolvimento: concepções e vivências de professores da educação infantil na Amazônia setentrional. Estudos e Pesquisas em Psicologia, 18(2), 588-607. Recuperado de http://scholar.google.com.br/citations?user=vlvp9mUAAAAJ\&hl=pt-BR

Brown, T., \& Link, J. (2016). The association between measures of visual perception, visual-motor integration, and in-hand manipulation skills of school-age children and their manuscript handwriting speed. British Journal of Occupational Therapy, 79(3), 163-171. doi:10.1177/0308022615600179

Cardoso, M. Н. (2019). Estratégias percepto-visomotoras para dificuldades com a escrita manual. Manual de estratégias para dificuldades e transtornos de atenção, leitura, escrita ortográfica e caligrafia. Ribeirão Preto: Booktoy.

Cardoso, M. H., Henderson, S., \& Capellini, S. A. (2014). Tradução e adaptação cultural brasileira do Detailed Assessment of Speed of Handwriting: equivalência conceitual e semântica. Audiology Communication Research, 19(4), 321-326. doi:10.1590/S2317-64312014000400001447

Fagaras, P. S., Rus, C. M., \& Vanvu, G. (2014). The Importance of Psychomotricity in Developing of Perceptual - Motor Structures. Procedia - Social and Behavioral Sciences, 149, 317-320. doi:10.1016/j.sbspro.2014.08.249

Fonseca, V. (2018). Neuropsicomotricidade. Ensaio sobre as relações entre corpo, motricidade, cérebro e mente. Rio de Janeiro: Walk.

Gonçalves, J. K. B., \& Sabatine, H. M. (2021). Estratégias de leitura: caminhos para autonomia leitura. Latin American Journal of Development, Curitiba, 3(4), 1743-1750.

Howe, T. H., Chen, H. L., Lee, C. C., Chen, Y. D., \& Wang, T. N. (2017). The computerized perceptual motor skills assessment: A new visual perceptual motor skills evaluation tool for children in early elementary grades. Research in Developmental Disabilities, 69, 30-38. doi:10.1016/j.ridd.2017.07.010 
Ingwersen, K. G., Vobbe, J. W., Pedersen, L. L., Sorensen, L., \& Wedderkopp, N. (2019). Effect of psychomotricity in combination with 3 months of active shoulder exercises in individuals with chronic shoulder pain: primary results from an investigator-blinded, randomized, controlled trial. Archives of Physical Medicine and Rehabilitation, 100, 2136-2143. doi:10.1016/j.apmr.2019.05.032

Maronesi, L. C., Figueiredo, M. O., Santos, E., Mazer-Gonçalves, S. M., \& Campos, S. D. F. (2015). Análise de uma intervenção dirigida ao desenvolvimento da coordenação motora fina, global e do equilíbrio. Cadernos de Terapia Ocupacional da UFSCar, 23(2), 273-284. doi:10.4322/01044931.ctoAO0537

Negreiros, F., Sousa, C. M., \& Moura, Francisca, K. L. G. (2018). Psicomotricidade e práticas pedagógicas no contexto da Educação Infantil: uma etnografia escolar. Revista Educação e Emancipação, 11(1), 130151. doi:10.18764/2358-4319.v11n1p130-151

Oliveira, A. C., César, C. P. H. A. R., Matos, G. G., Passos, P. S., Pereira, L. D., Alves, T., \& GuedesGranzotti, R. B. (2018). Hearing, language, motor and social skills in the child development: a screening proposal. CEFAC, 20(2), 218-227. doi:10.1590/1982-0216201820216617

Rossi, F. S. (2012). Considerações sobre a Psicomotricidade na Educação Infantil. Revista Vozes dos Vales da UFVJM, 1(1), 1-18. Recuperado de http://site.ufvjm.edu.br/revistamultidisciplinar/files/2011/09/Considera\%C3\%A7\%C3\%B5es-sobre-aPsicomotricidade-na-Educa\%C3\%A7\%C3\%A3o-Infantil.pdf

Sacchi, A. L., \& Metzner, A. C. (2019). A percepção do pedagogo sobre o desenvolvimento psicomotor na educação infantil. Revista Brasileira de Estudos Pedagógicos, 100 (254), doi:10.24109/21766681.rbep.100i254.3804

Rotta NT; Ohlweiler L; Riesgo RS. Transtornos da aprendizagem. Abordagem neurobiológica e multidisciplinar. Porto Alegre: Artmed, 2011.

Teodorescu, S., \& Popescu, O. (2014). Options to educate the intersegmental coordination and balance of children with intellectual disabilities by multi-sensory stimulation programmers. Procedia - Social and Behavioral Sciences, 117, 581-587. doi:10.1016/j.sbspro.2014.02.266

van der Maas, L., Koke, A., Bosscher, R., Twisk, J., Janssen, T., \& Peters, M. (2016). Body awareness as an important target in multidisciplinary chronic pain treatment: mediation and subgroup analyses. The Clinical Journal of Pain, 32(9), 763-772. doi: 10.1097/AJP.0000000000000320

Ventura, M. B. (2016). A importância da psicomotricidade no processo de alfabetização. (Trabalho de Conclusão de Curso - Licenciatura Plena em Pedagogia). Universidade Estadual Paulista Júlio de Mesquita Filho, Rio Claro, SP, Brasil. Recuperado de https://repositorio.unesp.br/bitstream/handle/11449/155735/000888718.pdf?sequence=1\&isAllowed=y

Zimermann, I.C.R., \& Moretto, M.T.S. (2021). Redescobrindo a leitura. Latin American Journal of Development, 3(5), 2819. 